CUADERNOS DE ESTUDIOS GALLEGOS, LXIV Núm. 130 (enero-diciembre 2017), págs. 199-227

ISSN: $0210-847 \mathrm{X}$

DOI: $10.3989 /$ ceg.2017.130.07

\title{
LA ACTIVIDAD TEXTIL EN OURENSE EN EL SIGLO XVI Y PRIMERAS DÉCADAS DEL XVII
}

Yolanda BARRIOCANAL LÓPEZ

Universidad de Vigo

ORCID iD: http://orcid.org/0000-0002-5497-7875

Copyright: (C) 2017 CSIC. Este es un artículo de acceso abierto distribuido bajo los términos de una licencia de uso y distribución Creative Commons Attribution (CC-by) España 3.0.

Cómo citar/Citation: Yolanda BARRIOCANAL LóPEZ, "La actividad textil en Ourense en el siglo XVI y primeras décadas del XVII", Cuadernos de Estudios Gallegos, 64, núm. 130 (2017), págs. 199-227, DOI: http://dx.doi.org/10.3989/ceg.2017.130.07 


\section{LA ACTIVIDAD TEXTIL EN OURENSE EN EL SIGLO XVI Y PRIMERAS DÉCADAS DEL XVII}

\section{RESUMEN}

Aportación al estudio de la actividad textil en Ourense en el siglo XVI y primeras décadas del XVII, a través de la documentación de archivo. Sobre la base de datos extraídos de los protocolos notariales se analizan los diferentes oficios, entre cuyas variedades textiles destaca la fabricación de terciopelos. Los resultados obtenidos en la investigación muestran la convivencia de dos sistemas de producción en el mismo espacio temporal. Por un lado, su fabricación por los talleres urbanos, y por otro, un sistema de producción organizado por los mercaderes ourensanos bajo fórmulas próximas al verlagssystem en el seno de las familias campesinas del coto de Sober (Lugo).

Palabras Clave: Técnicas textiles. Tejidos de seda. Terciopelo. Bordadores. Ourense. Siglos XVI y XVII.

\section{A ACTIVIDADE TÉXTIL EN OURENSE NO SÉCULO XVI E PRIMEIRAS DÉCADAS DO XVII}

\section{RESUMO}

Achega ao estudo da actividade téxtil en Ourense no século XVI e primeiras décadas do XVII, a través da documentación de arquivo. Sobre a base de datos extraídos dos protocolos notariais analízanse os diferentes oficios, entre cuxas variedades téxtiles destaca a fabricación de veludos. Os resultados obtidos na investigación mostran a convivencia de dous sistemas de produción no mesmo espazo temporal. Por una banda, a súa fabricación polos talleres urbanos, e por outra, un sistema de produción organizado polos mercaderes ourensáns baixo fórmulas próximas ao verlagssystem no seo das familias campesiñas do couto de Sober (Lugo).

Palabras clave: Técnicas téxtiles. Tecidos de seda. Veludo. Bordadores. Ourense. Séculos XVI e XVII.

\section{TEXTILE ACTIVITY IN OURENSE IN THE $16^{\text {TH }}$ CENTURY AND FIRST DECADES OF THE $17^{\mathrm{TH}}$}

\section{Abstract}

Contribution to the study of the textile activity in Ourense in the $16^{\text {th }}$ century and first decades of the $17^{\text {th }}$ century, through file documentation. The different trades are analysed on the basis of data extracted from notarial protocols, among whose textile varieties are highlighted the manufacture of velvets. The results obtained in the investigation shows the coexistence of two production systems in the same temporary space. On the one hand, their manufacture by urban workshops, and on the other, a production system organised by merchants from Ourense under formulas that were similar to the verlagssystem (putting out system) within farming families of the Sober estate. KeY words: Textile techniques. Silk cloth. Velvet. Embroiderers. Ourense. $16^{\text {th }}$ and $17^{\text {th }}$ centuries. 
Recibido/Received: 11/10/2016

Aceptado/Accepted: 04/05/2017

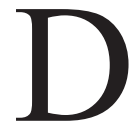

esde comienzos de la época moderna, los principales centros urbanos gallegos experimentan cierto dinamismo económico y diversidad socio-profesional, llegando a alcanzar algunos sectores artesanales, como el textil, un papel relativamente importante ${ }^{1}$. También en Ourense, aún siendo una ciudad pequeña, los oficios de este sector se encuentran entre los más representados, -ya desde finales de los tiempos medievales era el más preponderante entre las ocupaciones artesanas ${ }^{2}$ - aumentando este predominio a lo largo del siglo XVI, según reflejan los censos vecinales ${ }^{3}$.

El consumo de textiles creció a expensas de la necesidad, pues la ropa era un bien muy apreciado por las gentes de toda condición social, siendo muchas las evidencias documentales que atestiguan el valor que se le daba ${ }^{4}$. Las capas más populares constituían el soporte fundamental para la fabricación de lienzos y paños tradicionales, mientras que los géneros más lujosos estaban destinados a satisfacer la demanda de las clases adineradas con cierta entidad consuntiva, así como a cubrir las necesidades de vestiduras y ornamentos litúrgicos de los centros religiosos y parroquias del obispado.

\footnotetext{
1 La moderna historiografía tiende a acercarse cada vez más al estudio de la producción, distribución y consumo de paños. A efectos de establecer una perspectiva de historia comparada entre las ciudades gallegas durante la Edad Moderna en este sector artesanal, V., Juan Eloy Gelabert GonzÁlEz, Santiago y la tierra de Santiago de 1500 a 1640. (Contribución a la historia económica y social de los territorios de la Corona de Castilla en los siglos XVI y XVII), Sada. A Coruña, Ed. do Castro, 1982, págs. 242-249; Pegerto SaAVEdra Fernández, "Desarrollo y crisis de la industria textil gallega. El ejemplo de la lencería, 1600-1840”, Cuadernos de Investigación Histórica, 7 (1983), págs. 113-132; Joám CARMONA BADíA, El atraso industrial de Galicia. Auge y liquidación de las manufacturas textiles (1750-1900), Barcelona, Ariel, 1990; Pegerto SaAvedra Fernández, A Galicia no Antigo Réxime. Economía e Sociedade, III, A Coruña, Ed. Hércules, 1991, págs. 323-328.

2 Anselmo López Carreira, A cidade de Ourense no século XV. Sociedade urbana na Galicia baixomedieval, Ourense, Deputación Provincial de Ourense, 1998, pág. 201.

3 María López Díaz, "Ourense y su provincia al comienzo de los tiempos modernos", en Eiras Roel, Antonio (coord.), El Reino de Galicia en la época del emperador Carlos V, Santiago de Compostela, Xunta de Galicia, 2000, pág. 535.

4 Pegerto SaAvedra Fernández, "El textil en la Edad Moderna", en Con-Fío en Galicia. Vestir Galicia. Vestir o Mundo, Santiago de Compostela, Xunta de Galicia, 2016, págs. 243-257.
} 
En los protocolos notariales ourensanos y libros parroquiales queda constancia de muchos de estos artesanos y de su variada especialización. Pero, como sucede con otros oficios, no hubo normativas específicas que velaran y protegieran sus intereses comunes. Ni siquiera los bordadores, aún en los momentos de mayor auge de su ejercicio, tuvieron cofradía propia. De forma que tanto los mercaderes tratantes en paños y mercería, como los "sastres, calceteros, tundidores, tecelanes, albarderos, sombrereros, cordoneros, merceros y otras qualesquiera personas que cosiesen con aguja", estaban agrupados en la cofradía de Santa María Madre, la más importante y de mayor duración de la ciudad, con sede en la iglesia del mismo nombre. Se dieron nuevas ordenanzas en 1588, por ser las hechas antiguamente "muy viejas y no se entender". Cada año, al frente de la misma, se nombraba mayordomos y vicarios, según era uso y costumbre en este tipo de asociaciones, con la obligación de tomar capellanes para las misas, disponer los sepelios de los cofrades y nombrar para la danza y regocijos de la cofradía por Pascua de Flores y Corpus. La reglamentación tenía una finalidad devota, sin encontrarse datos sobre el funcionamiento interno de la cofradía, ni referencias a la obligatoriedad de un examen para alcanzar el grado de maestro. Las ordenanzas señalan sólo el pago de diferentes cuotas según la categoría profesional: una libra de cera los obreros y dos libras los aprendices de cualquier oficio que perteneciese a la cofradía; si el aprendiz no lo pagase, el maestro estaba obligado a abonarlo por él al mayordomo, sin poder comenzar a enseñarle el oficio hasta satisfacer la cuota.

\section{Mercaderes de tejidos}

El comercio ejerció una influencia decisiva en la consolidación y especialización del arte textil. Además del consumo de paños extranjeros, preferentemente de Flandes, Francia e Inglaterra, el gran centro de contratación de tejidos estaba en Medina del Campo, Villalpando y Medina de Rioseco. A estas villas castellanas y sus ferias acudían los mercaderes ourensanos para abastecerse de paños ${ }^{6}$, siendo también muchos los comerciantes procedentes de Castilla y Portugal dedicados a este negocio que se fueron instalando en la ciudad.

\footnotetext{
5 Miguel Ángel González García, "Unas ordenanzas de la cofradía orensana de Santa María Madre, del siglo XVI", Boletín de Estudios del Seminario "Fontán-Sarmiento, 14 (1993), págs. 8-12.

6 Como ejemplo, en 1573, el mercader Francisco Enríquez se obliga a pagar a Miguel Gómez, vecino de Rioseco, una parte del coste de paños de Toledo que sumaban 94.367 maravedís (AHDO, Ourense, Prot. de Gómez Cid. 13 enero 1573). En 1574, el mercader Leonardo de Mena da poder a su hijo Simón de Mena para ir a las ferias que se hacen en el Reino de Castilla y tomar y recibir fiado de cualquier persona, calidad y condición, de paños, sedas y dinero (AHDO, Ourense, Prot. de Gómez Cid, 9 febrero 1574). En 1589, el mercader Francisco Enríquez da un poder a su hijo, Francisco García Enríquez, para cobrar de los mercaderes de Medina de Rioseco y otros lugares, 200.000 maravedís de paños (AHDO, Ourense, Prot. de Diego Ogea, 6 octubre 1589).
} 
El surtido de toda suerte de tejidos y las cantidades de mercancías que aparecen en la documentación de estos mercaderes, avala la importancia de sus negocios. Sirva de ejemplo el variado surtido que muestra el inventario de bienes del tendero Pedro Cotán "o Mozo", hijo de otro mercader del mismo nombre, en su tienda de la Praza do $\mathrm{Campo}^{7}$. O el testamento del rico mercader Lisuarte de Mena, oriundo de Chaves, de 1561, donde declara que en la tienda de su casa, lindera con la anterior, tenía paños españoles y extranjeros, surtidos y variados, por valor de 2.000 ducados $^{8}$.

Lisuarte de Mena pertenecía a una destacada familia de comerciantes portugueses que enraizó con éxito en Ourense, uniéndose por vía matrimonial con otras estirpes de mercaderes locales, alcanzando así su plena integración. Era hijo de Simón de Mena, de Chaves, y de Ana de Buendía, y estuvo casado con Leonor Enríquez, hermana de los mercaderes Luis de Paz y Francisco Enríquez, sobrina a su vez del también mercader Manuel Enríquez, que dispuso de capilla funeraria propia en el claustro del convento de San Francisco'. Tras su violenta muerte, recibió sepultura en dicha capilla, así como su viuda, que viviría aún largos años prosiguiendo con los negocios de su difunto marido ${ }^{10}$.

Sus hermanos, Leonardo de Mena, casado con Gracia de Fonseca, y Manuel Lope de Mena, se dedicaron también al comercio, permitiéndoles su acomodada situación el manejo de un capital suficiente como para asumir riesgos con operaciones de préstamos, pues además de su dedicación al comercio con paños y toda clase de mantenimientos, su alta posición permitía a estos mercaderes mantener otros negocios, llegando a detentar importantes patrimonios. Como ejemplo, en 1579, Leonardo de Mena se da por pagado de 50.000 maravedís que le debía Diego de Oca Sarmiento, señor de Celme, habitante del palacio de los Oca, que le había prestado en dinero, paños, sedas y otras cosas para él y su casa antes de su fallecimiento; lo cual le paga su hijo Álvaro de Oca Sarmiento ${ }^{11}$.

Manuel Lope de Mena mandó enterrarse en la capilla de San Luis del monasterio franciscano, al ser su mujer, Elena Núñez, sobrina del afamado médico Jerónimo Díez, oriundo de Villarreal, en Oporto, quien la mandó edificar. Casó

\footnotetext{
AHPO, Ourense, Prot. de Juan Soto. 1575, fol. 70. V., Olga Gallego DomínguEz, A cidade de Ourense. Unha visión a través dos séculos, Ourense, Museo Arqueolóxico Provincial de Ourense, 2001 (Boletín Auriense. Anexo 27), pág. 251.

8 AHPO, Prot. de Juan Soto, 1561, fols. 257, 284. V., Olga Gallego Domínguez, A cidade de Ourense..., págs. 96, 245.

9 La capilla, bajo la advocación de Nuestra Señora de Asunción, serviría de modelo a la que en 1562 concertaron los cumplidores del sastre Gregorio da Fonte en el mismo convento. O. GALLEGo DomínguEZ, A cidade de Ourense..., pág. 188.

${ }^{10}$ Olga Gallego DomíngueZ, Historia da muller. Mulleres ourensás dos séculos XIV-XVIII, Ourense, Grupo Marcelo Macías, 2008, págs. 214-218.

11 AHDO, Ourense, Prot. de Gaspar Salgado, 1579-80.
} 
en segundas nupcias con el mercader Cristóbal de Buendía, perteneciente a otra saga de mercaderes portugueses, llegados a la ciudad hacia el año 1560, que compartía el negocio con sus hermanos, los mercaderes Manuel López de Buendía y Lope de Buendía.

A su vez, Simón de Mena, hijo de Leonardo de Mena, estuvo casado con Catalina Pereira, viuda del también mercader Alonso Fernández, disponiendo de un patrimonio importante. Entre sus bienes figura una granja en la Puente da Loña, para la que en 1589 concierta al maestro de cantería Gergorio Fatón, vecino de Barbadás, un lagar de piedra de grano, una puerta y dos ventanas de asiento para el primer piso y alto de la torre de la casa de dicha granja ${ }^{12}$.

Puede decirse que estos acomodados hombres de negocios, de los que aquí se da solo un breve esbozo, junto a los comerciantes autóctonos, desarrollaron un importante papel en la producción especializada de ciertos tejidos de lujo, caso del terciopelo, mediante la organización de un sistema de trabajo basado en la producción a domicilio, entregando a los tejedores el género, que después recogían ya labrado para su comercialización.

\section{TECELANES}

La fabricación de tejidos de lino (estopas y lienzos), materia textil por excelencia en Galicia, con toda su amplia gama de elaboraciones, ocupó a buen número de artesanos por abarcar su consumo a todo el espectro social.

En Ourense, desde finales del siglo XV este artesanado estaba en manos de foráneos. En los Padrones de 1487 y 1490 figura un "teçelán françés" en la rúa de Cima y Tendal de Figueira. En el de 1502 figura como vecino en la rúa da Barreira, el tecelán Lebín o Levín, nombre de resonancias judías, y entre 1510 y 1513 en la rúa das Chousas. Hizo testamento en 1508, pidiendo ser enterrado en el cementerio de la iglesia de la Trinidad, "onde fasen sepultados meus fillos", mandando a su criado Juan, tecelán, “o meu sayo o gibón”, dejando por universal heredera a su hija Isabel ${ }^{13}$.

Entre los procedentes del norte de Europa, los flamencos tuvieron una clara hegemonía, moviéndose por el territorio gallego según las oportunidades. De la presencia de estos flamencos y de sus estrechos contactos con otros miembros de la colonia, ofrece un buen ejemplo el testamento del tecelán Jorge Flamenco, de 1506. En él mandaba enterrarse en el monasterio de San Francisco. Dejaba a Adrián Flamenco, su compadre, vecino de Fontefría, la "capa Roan flamenca con su guarnición", y a Juan Flamenco, su oficial y criado, el "gibon de chamelote".

\footnotetext{
12 AHDO, Ourense, Prot. de Diego Ojea (1588-89), 13 octubre 1589.

13 AHPO, Ourense, Prot. de Juan González de Cervela, 17 octubre 1508, fol. 51.
} 
Nombra heredera a su mujer Aynés, flamenca, y cumplidores al zapatero Gutierre y a Juan Flamenco. La declaración de deudas revela también estrechas relaciones con otros compatriotas: Mateus Alemán le debía 16 reales; Juan Flamenco, vecino de Fontearcada, 11; Giraldo Flamenco, vecino de Armariz, 9 reales; Estebo francés, "pelujero", 25 maravedís; Jácome Flamenco, tecelán, vecino de Santiago de Parada, 2 reales; Rodríguez González, platero, un real y medio; mestre Juan, vecino de Seixalvo, 12 pares de blancas y 189 reales, y Enrique Alemán, vecino de Pontevedra, 11 reales que le había prestado en Santiago en casa de mestre Ambrosio ${ }^{14}$.

No murió entonces, pues en 1515 figura en la rúa das Chousas, y en 1523, como testamentario del tendero Juan Núñez, vendiendo una viña blanca en Forno Telleiro, de doce o trece cavaduras, forera de Pedro de Rocabo, notario del número de Ourense ${ }^{15}$. Resulta también evidente la amistad mantenida con el imaginero Cornielles de Holanda, uno de los principales escultores de la Galicia del momento, del que actúa como su fiador en el concierto con el entallador Álvaro Fernández de una caja para un grupo escultórico del Santo Sepulcro con destino a la capilla de los Sandoval en el claustro del monasterio franciscano ${ }^{16}$, y nuevamente, en una carta de pago por un retablo para el abogado Francisco Méndez en el mismo convento ${ }^{17}$. La última noticia data de 1529 , en que Jorge Flamenco da poder a Felipe Flamenco, para un pleito sobre bienes y contratos que tenía en la ciudad de Tui ${ }^{18}$.

En el Padrón de 1515 figuran los tecelanes Jácome y Estebo en la rúa das Chousas, pudiendo ser el primero el mismo Jácome Pérez que en 1550 aparece otorgando un poder a procuradores en la Real Audiencia, para un pleito sobre reclamo de cantidades ${ }^{19}$. En el Padrón de 1530 se anota a maestre Juan, tecelán, en la rúa de la Carnicería, al que nuevamente encontramos en 1550 como testigo en un poder de Francisca de Villaroel, mujer de Vasco Feijoo, hija de Miguel García de Cisneros y de Leonor de Villarroel, vecinos que fueron de la villa de Cisneros, para pedir los bienes que le pertenecían por herencia de sus padres ${ }^{20}$.

\footnotetext{
${ }^{14}$ Firma autógrafa en letra gótica. AHPO, Ourense, Prot. de Juan González Cervela, 4 julio 1506.

15 AHPO, Ourense, Prot. de Juan de Cervela, 18 marzo 1523, fol. 305.

16 AHPO, Ourense, Prot. de Juan González Cervela, 1521, fol. 80. V. Pablo PÉrez Costanti, Diccionario de artistas que florecieron en Galicia durante los siglos XVI y XVII, Santiago, Imp. del Seminario C. Central, 1930, pág. 288; O. Gallego Domínguez, A cidade de Ourense ..., pág. 184; O. Gallego Domínguez, Historia da muller..., pág. 274; Yolanda BARRIOCANAL LóPEZ, La actividad escultórica en Ourense, del Renacimiento al Barroco, Ourense, Consejo Superior de Investigaciones Científicas, Grupo Marcelo Macías, 2016, pág. 151. 17 AHPO, Prot. de Juan González Cervela, 1524, fol. 42. V., O. Gallego Domínguez, A cidade de Ourense..., pág. 188 .

18 AHDO, Ourense, Prot. de Juan González de Cervela (1529-30), 1529.

19 AHPO, Ourense, Prot. de Pedro de Riocabo, 1550.

20 AHPO, Ourense, Prot. de Juan Blanco, 22 abril 1550, fol. 7.
} 
En la segunda mitad de siglo se documenta a Juan Dorliens, del que en 1562 consta una obligación en su contra, del doctor Jerónimo Díaz, por un jarro de plata $^{21}$. En 1564, Domingo López arrienda a “Juan de Horliens, texedor", su casa en Cimadevila, por un año, en 6 ducados $^{22}$. En la misma fecha, el regidor Gómez Pérez comparece ante el juez Vasco de Puga de Sandoval, saliendo fiador de Alonso Bermúdez, escribano real, preso en la cárcel a petición de Juan Pernas y Juan d'Orliens ${ }^{23}$. De 1570 data una carta de poder de Juan Dorliens, tecelán, como marido de Elena Juárez, a procuradores de causas de Ourense y de la Real Audiencia, para cierto pleito con Teresa Rodríguez, criada de Gaspar de Sequeros, donde consta que no sabe firmar ${ }^{24}$. La última noticia data de 1573 , en que Juan de Horliens se obliga a pagar al entallador Guillén Rojas, vecino de A Coruña, 9 ducados del resto de seis piezas de cordellate que le había vendido en precio de 36 ducados $^{25}$.

Los talleres se distribuían por toda la ciudad, siendo frecuentes los cambios de domicilio ${ }^{26}$, como se comprueba en el caso del tecelán Guillén Bobín, a quien en 1568, Juan Rodríguez de Soto, escribano de S. M., como procurador de su madre, Constanza Rodríguez, le arrienda, por un año la casa del Barrio Nuevo, excepto el lagar y tinaja, en 8 ducados $^{27}$. En 1576, Inés López de Ceboleiros, viuda, arrienda a Guillén Boby, tejedor, las casas en la Plaza de la Sal, por un año, en 5 ducados $^{28}$. Otro artesano, Pedro de Ayra, "tejedor de lienços y alimanisco", y Luisa Fernández, su mujer, aparecen en 1605 en el Eiró do $\mathrm{Sal}^{29}$.

También constan maestros avecindados en las cercanías de la ciudad, como Jácome Fernández, "flandesco", vecino de San Vicente de Graíces (A Peroxa), quien en 1560 vende a Pedro López de la Barrera, canónigo de Ourense y rector de dicha parroquia, "la my viña blanca y prieta con su casa llana", junto a la villa ${ }^{30}$. O el tecelán Francisco Borgoñón, en cuyo taller puso Fernán de Villar, en 1566, por moza aprendiz a su criada Ana de Prados, un año y medio, por 5 ducados $^{31}$.

\footnotetext{
${ }_{21}$ AHDO, Ourense, Prot. de Jácome de Faro, 1562.

22 AHPO, Ourense, Prot. de Fernando López. Papeles sueltos, 7 septiembre 1564.

${ }^{23}$ AHPO, Ourense, Prot. de Juan Soto. 1564, fol. 159.

24 AHDO, Ourense, Prot. de Francisco García. 11 agosto 1570, fol. 40.

25 AHPO, Ourense, Prot. de Juan Soto (1571-1574), 11 julio 1573.

${ }^{26}$ Hay noticia de una "puerta de los Tecelanes", de la que se habla en un acuerdo de 1637, con motivo de la vigilancia establecida a causa de la peste existente en Málaga, y que pudiera corresponder con la que en 1599 se llamaba "puerta de los Tejedores", aludiendo a la vecindad de algunos de estos artesanos, que, aunque no ha sido posible su identificación, probablemente corresponda con la de San Francisco o Cimadevila. V., Olga Gallego Domínguez, "Torres, puertas y cerca de la ciudad de Orense”, Boletín Auriense, II (1972), pág. 269.

27 AHPO, Ourense, Prot. de Juan Soto, 8 mayo 1568, fol. 174.

${ }_{28}$ Firma "Gilens Bobín". AHPO, Ourense, Prot. de Rodrigo de Puga, 26 agosto 1576, fol. 180.

29 AHDO, Ourense, Prot. de Gaspar Rodríguez, 1605.

${ }^{30}$ AHPO, Ourense, Prot. de Juan Blanco, 7 diciembre 1560, fol. 101.

31 AHPO, Gustei. Prot. de Fernando Ares, 9 enero 1566, fol. 1.
} 
Dos años después, Alonso Francisco, vecino del coto de Gustei, vende a Francisco Borgoñón, "teçelán", vecino de dicho coto, y a su mujer Olinda Vázquez, la corte y solar que estaba en medio de la casa de ambos, que salía con puerta al camino público de dicho coto, en 6 ducados $^{32}$.

En los talleres, junto a los maestros expertos, había jóvenes en diferentes etapas de su aprendizaje. Las condiciones en las que transcurría su permanencia en casa del maestro no diferían, en lo sustancial, de las que se daban en otros oficios, a no ser la corta duración. Así, en 1581, el tejedor Juan Tizado se obligaba a enseñar a Juan de Touzas, criado del mercader Gabriel Álvarez, el oficio de tejedor de alemanisco, lienzo, estopa y pañizuelos, en el plazo de un año, por 8 ducados. El maestro correría con su manutención, dándole de comer, beber y cama ${ }^{33}$.

No falta la mano de obra femenina, según consta en la obligación de aprendiz, suscrita en 1602, entre el tecelán Francisco Suárez con María Rodríguez, de Ourense, por la que se obligaba a enseñarle el oficio de "texedora" de lienzos y estopas, a excepción de alemaniscos, en un año, y tenerla en su casa dándole de comer, por 9 ducados ${ }^{34}$.

También el tecelán Roque Rodríguez se obligaba, en 1603, a enseñar a Bárbara de Cantona, vecina de Tioira, el oficio de tejedora de lienzos en año y medio, por 12 ducados y medio ${ }^{35}$. En otra obligación del mismo año, entre Roque Rodríguez, tejedor de lienzos y alemaniscos, con Juan González, natural de Santa María de Carballeda (Piñor), como principal, y Alonso Varela, vecino de Gontán, como su fiador, se compromete a enseñarle el oficio de tejedor de lienzos gruesos y delgados y alemaniscos, en año y medio, y a darle de comer y cama, por 17 ducados $^{36}$. En 1618, Roque Rodríguez aparece como fiador del sastre Antonio Fernández, obligándose a pagar al mayordomo de rentas reales de Ourense 12 ducados por razón del arrendamiento de la alcabala de los lienzos que se vendían en la ciudad en dicho año ${ }^{37}$.

\section{TEJEDORAS DE TOCAS}

Las piezas pequeñas, como cintas, bolsas o tocas, podían hacerse con facilidad en casa y probablemente por un solo bordador. El número de mujeres dedicadas a estos menesteres debió ser abundante, siendo el oficio de tejedora de tocas exclusivamente femenino, como se desprende de varias escrituras de aprendizaje y

\footnotetext{
32 AHPO, Ourense, Prot. de Juan Soto, 4 mayo 1568, fol. 124.

33 AHPO, Ourense, Prot. de Juan Soto, 9 noviembre 1581, fol. 107.

34 AHDO, Ourense, Prot. de Francisco García, 25 noviembre 1602, fol. 889.

35 AHDO, Ourense, Prot. de Francisco García, 8 diciembre 1603.

36 AHDO, Ourense, Prot. de Francisco Fernández, 8 marzo 1603, fol. 88.

37 AHDO, Ourense, Prot. de Francisco Fernández, 8 enero 1618, fol. 63.
} 
conciertos de servicio. Así, en 1569, Rodrigo da Ribeira, criado que había sido del deán Rodrigo de Mendoza, e Isabel Rodríguez, "texedora de tocas", su mujer, se conciertan con Francisca Míguez, hija que había quedado de Juan Míguez, vecino de Moreiras, estante en Ourense, para enseñarle en el plazo de un año el oficio de "texedora de tocas", dándole de comer y beber, por 6 ducados $^{38}$.

En 1595, la viuda de Manuel Rodríguez y el matrimonio formado por Bartolomé López y María Rodríguez, se conciertan en que María tome a su cargo por "deprendiz" para enseñar el oficio de tejedora de tocas a Isabel Rodríguez, que había servido al dicho Manuel de moza de servicio. La tendría en su casa año y medio, dándole de comer, beber y posada "como es costumbre en las demás que deprenden dho oficio", por 8 ducados $^{39}$.

En 1601, Catalina Rodríguez, tejedora de tocas, viuda que quedó de Bartolomé Cabreiro, arriero, se concierta con Antonia Rodríguez, moza soltera de la feligresía de Gundivós, jurisdicción de Monforte de Lemos, para enseñarle en un año "a texer tocas de algodón y de seda y de otra qualquiera obra", por 10 ducados en dos pagas, de manera que fuera buena obrera y ganase jornal. Era condición que Catalina le diese de comer, beber, cama y tratarla como era costumbre. Si no la enseñase en el tiempo convenido el más que fuese necesario se lo pagaría como se solía pagar a una obrera ${ }^{40}$. Al año siguiente, la misma tejedora se concierta con Catalina Pérez, moza soltera, para enseñarle el oficio en un año "a vista de maestras del". Durante el tiempo de aprendizaje la tendría en su casa y servicio, dándole de trabajar, comer, beber, posada y cama, por servicio durante ese año y 10 ducados en dinero, los cinco primeros dentro de los cuatro días siguientes y el resto para Navidad. Si no aprendiese el oficio en dicho tiempo, la tendría en su casa pagándole el salario que ganaban las demás oficialas, sin que la aspirante pudiera ausentarse, bajo pena de poder tomar otra oficiala y pagarle el salario que se concertase a su costa ${ }^{41}$.

En 1603 la tejedora Isabel Martínez toma por aprendiz a Catalina Fermosa, para enseñarle el oficio de tejedora de tocas de algodón por 4 ducados y medio durante un $\mathrm{año}^{42}$. Finalmente, en 1604, Juan López de Banga, procurador de causas de Ourense, pone por aprendiz del oficio de "texedora de tocas" con Antonio Macías, a María Martínez, vecina de Ourense, durante un año, dándole cama y no otra cosa, por 6 ducados $^{43}$.

\footnotetext{
38 AHPO, Ourense, Prot. de Juan Soto. 25 mayo 1569, fol. 137.

39 AHPO, Ourense, Prot. de Pedro de Lemos, 1595, fol. 422.

${ }^{40}$ AHDO, Ourense, Prot. de Juan Sotelo, 20 junio 1601.

${ }^{41}$ AHDO, Ourense, Prot. de Francisco Fernández, 12 abril 1602, fol. 92.

${ }^{42}$ AHDO, Ourense, Prot. de Francisco García, 9 octubre 1603.

43 AHPO, Ourense, Prot. de Pedro de Lemos, 18 febrero 1604, fol. 626.
} 


\section{TEJEDORES DE TERCIOPELO}

La creciente demanda de prendas de seda, producto suntuario por excelencia, hace que la nómina de tejedores de este textil abunde en la documentación a partir de la segunda mitad del siglo, particularmente los dedicados al terciopelo, el tejido favorito de la clientela y el más utilizado en los ornamentos litúrgicos.

Los protocolos notariales proporcionan cumplidos datos acerca de Francisco Rodríguez, natural de San Salvador de Sabucedo (Porqueira), quien a tenor de la frecuencia con la que aparece en la documentación, pasa por ser uno de los tejedores principales del momento.

En 1553 ya ejercía como maestro en su oficio, año en que aparece firmando un contrato de aprendizaje con el escribano Juan do Río, vecino de Santiago, para enseñar a Francisco do Río, su hermano, el oficio de tejedor de seda "de terciopelo y tafetán y todas las otras cosas necesarias al dicho oficio, así de dar la tinta a las sedas como lo demás", en seis años, dándole de comer y beber, y 8 ducados para vestidos y calzados ${ }^{44}$.

En 1567 figura como portero del ayuntamiento ${ }^{45}$, prueba del desempeño ocasional de otros empleos, así como de su reputación y estima social. En 1569 es nombrado como "hombre bueno" para hacer partija y tasación entre los herederos de los bienes dejados por Teresa Fernández de Malburgo y Bartolomé Álvarez ${ }^{46}$. Y en 1574 aparece como fiador del escribano Bartolomé Álvarez, en quien se había rematado la renta de una herrería en las afueras de la ciudad ${ }^{47}$.

De su trabajo como sedero se tienen pocas noticias. Solo consta el concierto hecho en 1567 con el mercader Jusuarte Enríquez para hacerle veinte varas de terciopelo negro, "bueno de dar y tomar y de buen negror a vista de oficiales", comprometiéndose a entregarle la mitad para el día de Navidad y el resto para febrero del año siguiente, por 18 reales la vara; con la condición de que si no le diese el terciopelo en el plazo convenido, el mercader lo pudiese comprar a su costa al precio que lo hallase ${ }^{48}$. Pero, pese a la falta de datos, debió de ser uno de los tejedores más activos y de mayor fama a juzgar por su actuación como testigo en operaciones de otros de su oficio.

Todo parece indicar que también trabajaba con independencia, comprando la seda en crudo y tejiendo los géneros que le encargaban sus clientes, sin que mediase un contrato que fijase las obligaciones de las partes. Hay noticia de la adquisición de diferente género en 1586 , en que se obliga a pagar al mercader

\footnotetext{
${ }_{44}$ AHPO, Ourense, Prot. de Juan Fernández de Luaces, 4 febrero 1553, fol. 12.

45 AHPO, Ourense, Ayuntamiento de Ourense. Mazo de escrituras, 1567.

46 AHDO, Ourense, Prot. de Luis Fernández. 1569, fol. 1.

47 AHPO, Ourense, Prot. de Juan Soto (1574-1575), 16 marzo 1574.

48 AHDO, Ourense, Prot. de Benito Fernández Ojea, 9 noviembre 1567.
} 
Antonio Vázquez tres varas de palmilla y cuatro y media de pardillo ${ }^{49}$, y nuevamente a finales del mismo año, en que paga al mercader 199 reales por tejidos de mezcla, estameña y anascote ${ }^{50}$.

Las fuentes documentales permiten comprobar que llevó una vida con cierto acomodo, añadiendo a los beneficios de su trabajo los procedentes de bienes rústicos en Sabucedo de Limia, su lugar de origen, donde disfrutaba de un pequeño patrimonio. En 1563, su padre, Francisco Daguionaga, le vende una heredad en As Azenas, término del coto de Sabucedo, en 10 ducados, que le paga con una taza de plata dorada ${ }^{51}$. Una vez fallecidos sus padres procede a la venta de los bienes que le pertenecían por herencia: en 1568 vende a su sobrino Lois Rodríguez, vecino del coto de Porqueira, la mitad de una "cortin" llamada das Ribas, en la jurisdicción del coto de Sabucedo, de fanega y media - la otra mitad pertenecía a su hermano Simón Rodríguez- en 26 ducados $^{52}$; en 1574, vende a Luis Dalbán, escribano, vecino de Sabucedo de Limia su casa de morada en el mismo lugar, con su horno y corral, junto a otras heredades rústicas por 95 ducados, recibiendo en pago una taza, un salero y una jarra de plata dorada ${ }^{53}$.

No faltan pequeñas operaciones, como la entrega en 1576, a Pedro Gutiérrez, de una vaca "bermella", de seis años, muy buena, y un becerro, para que los criase, repartiéndose las crías entre ambos ${ }^{54}$. Aunque sus negocios se dirigieron principalmente a la adquisición y arrendamiento de fincas rústicas en los términos de la ciudad y sus alrededores. En 1578 da poder a procuradores de causas de Ourense y de la Real Audiencia para cierto pleito que trataba con el bachiller Figueroa, como tutor del hijo que quedó de Pero Ares de la Iglesia, sobre una viña que le pedía $^{55}$. En 1579, arrienda la mitad de una bodega en la calle da Obra ${ }^{56}$. En 1583 vende a Francisco Carrero una viña en Forno Telleiro, de diecisiete cavaduras, en 80 ducados $^{57}$. Poseía también una viña en el Couto, para la que en 1581 contrata una pared al cantero Estebo Vázquez ${ }^{58}$. En 1585, Antonio Pereira Meneses le arrienda doce fanegas de centeno de renta en Santa María da Barra (Coles), por dos años, en 12 ducados $^{59}$. Un año después da en arrendamiento a Alejandro Falecón y a Ana de Alén, su mujer, vecinos de Santiago das Caldas, una viña,

\footnotetext{
49 AHDO, Ourense, Prot. de Gaspar Salgado, 7 abril 1586.

50 AHDO, Ourense, Prot. de Pedro Feijoo, 22 diciembre 1586, fol. 460.

51 AHDO, Ourense, Prot. de Benito González Ojea, 1563, fol. 243.

52 AHDO, Ourense, Prot. de Gómez Cid, 1568, fol. 287.

53 AHDO, Ourense, Prot. de Gaspar Salgado, 1574.

${ }^{54}$ AHPO, Ourense, Prot. de Juan Soto, 19 julio 1576, fol. 237.

55 AHDO, Ourense, Prot. de Juan Sotelo, (1577-78), 1578.

56 AHDO, Ourense, Prot. de Gaspar Salgado, 1579-80.

57 AHDO, Ourense, Prot. de Luis Fernández, 1583, fol. 557.

58 AHPO, Ourense, Prot. de Juan Soto (1581-1584), 1581, fol. 129.

59 AHDO, Ourense, Prot. de Luis Fernández, 26 marzo 1585, fol. 74.
} 
heredad y casa, en el lugar de Porto, junto a la casa de la barca, por nueve años, de la manera que lo tenía en arrendamiento el sillero Francisco López, por un moyo de vino blanco y otro de tinto que le pagarían cada año por las vendimias ${ }^{60}$. Y en 1587, Juan Fernández de Castro, en quien se había rematado las dos tercias partes del beneficio de Santa María de Reza, perteneciente al arcediano de Baroncelle, tesorero de la catedral de Sevilla, D. Juan de Noboa Villamarín, se las arrienda al sedero en 96 ducados ${ }^{61}$.

Tuvo taller y vivienda propia en una de las calles más señoriales de la ciudad, según consta de la venta que el mercader de paños y seda, Francisco Rodríguez, le hace en 1571 de unas casas en la Corredera que habían sido del cantero Juan de Pámanes, maestro de las obras del monasterio de Celanova ${ }^{62}$. Diez años después, el sedero daba poder a procuradores para un pleito con el procurador Juan Rodríguez Soto, por la tienda que "esta debaxo de mis casas de morada"63.

En octubre de 1589, Francisco Rodríguez dicta su testamento ${ }^{64}$. Mandaba enterrarse en la iglesia de Santa María Madre, en una sepultura que estaba junto a la puerta de la entrada del aposento del preceptor de gramática "que tiene dos piedras partidas por medio", donde estaba sepultada su madre, Ana Rodríguez, y su hermano Tomás Rodríguez, clérigo.

Dice que estuvo casado en primeras nupcias con Aldonza Cordeira, y en segundas, con María Rodríguez. Declara haber comprado la casa de la Corredera en que vivía, en 200 ducados, y que había gastado mucho en pleitos y reparos de ella. Que el Lcdo. Luzón, con el edificio de sus casas, le hizo daño y perjuicio a los suyos y tenían pleito sobre ello, mandando que se siguiera para deshacer el agravio. Había vendido los bienes heredados de sus padres en Sabucedo de Limia para hacer ciertas compras. Deja usufructaria de sus bienes a su mujer, y herederos a sus sobrinos Gonzalo Rodríguez y Catalina Rodríguez, con la obligación de mandar decir doce misas rezadas anuales en dicha iglesia.

No murió entonces, pues en septiembre, el arriero Juan de Bouzas se obliga a pagarle 54 reales del resto de los 108 que Domingo Fernández, portugués vecino de Carril, como principal, y el otorgante, como su fiador, le debían por razón de una escritura de obligación, cuyo plazo había ya pasado ${ }^{65}$. Siete días después da su poder al sastre Alonso López y a su "criado" Rodrigo da Carreira, para cobrar

\footnotetext{
${ }_{60}$ AHDO, Ourense, Prot. de Luis Fernández, 24 febrero 1586, fol. 186.

${ }^{61}$ AHDO, Ourense, Prot. de Luis Fernández, 30 julio1587, fol. 104.

62 AHPO, Ourense, Prot. de Juan Fernández, 3 septiembre 1571, fol. 121. Sobre la actividad de este maestro de obras en el monasterio de Celanova. V. Miguel Ángel GonzÁlez GArCía, "El arquitecto Juan Ruiz de Pamanes en Celanova", Rudesindus: miscelánea de arte e cultura, 8 (2012), págs. 135-140.

63 AHPO, Ourense, Prot. de Juan Fernández, 16 junio 1581, fol. 59.

${ }^{64}$ AHPO, Ourense, Prot. de Pedro López de Soto, 10 octubre 1589, fol. 37.

65 AHDO, Ourense, Prot. de Luis Fernández, 5 septiembre1589, fol. 435.
} 
cualquier deuda y la renta que tuvo arrendada perteneciente a los hijos de Mendo de Puga ${ }^{66}$.

Es su último acto conocido. Dos meses después, su viuda hace testamento ${ }^{67}$. Declara que Francisco Rodríguez fue su segundo marido, del que no había heredado bienes, habiendo estado casada anteriormente con Jácome de Deza, barbero, del que le quedó una hija que había muerto. En el mismo año da poder a su sobrino Juan Rodríguez Salgado para vender al escribano Luis Fernández cuarenta moyos de vino blanco que tenía en tres cubas, una en la bodega de Luis de Villamarín y Benito de Prado, en la rúa de los Zapateros, y otras dos en la bodega de Arcedianos, por 1.200 reales $^{68}$.

Los protocolos notariales solo despejan la presencia de otro tejedor, con una situación más modesta, Juan Rodríguez, quien en 1562 se concierta con el mercader Tristán de Mena para hacerle cuarenta varas de terciopelo negro, de un pelo, "que sea bueno de dar y tomar entre mercaderes". Le entregaría diez varas para septiembre y otras diez para el día de San Martiño, por 30 ducados. Las restantes se las daría para el día de Pascua y mayo del siguiente año, por 18 reales cada vara, que le iría pagando según le fuera entregando el terciopelo ${ }^{69}$.

En 1569, su mujer, Lucía Álvarez, enferma en cama, solicita licencia para arrendar una viña para su mantenimiento, puesto que su marido se había ausentado de la ciudad por deudas y delitos hacía seis meses y no le había dejado dinero alguno con que poder mantenerse, y era vieja y enferma y tenía bienes suyos propios que llevó en dote ${ }^{70}$.

El tejedor regresó a Ourense, pues en 1604 vende 50 reales de censo en dos años a favor de Gonzalo de Puga y Noboa, abad de Santa María de Mugares ${ }^{71}$.

\section{Tejedores de terciopelo en el Coto de Sober (Lugo)}

El otro foco para la producción de terciopelo tuvo su centro de operaciones en el condado de Lemos, donde la crianza y labrado de la seda contaban con cierta tradición. Tanto los escritos de los autores del momento como después los de los ilustrados se hacen eco del trabajo de la seda en los valles de Monforte, Sober,

\footnotetext{
${ }_{66}$ AHDO, Ourense, Prot. de Luis Fernández, 12 septiembre 1589, fol. 669.

${ }^{67}$ Manda enterrarse en el convento de San Francisco. Deja como cumplidores de su testamento a su hermano Francisco Rodríguez y a su sobrino, Juan Rodríguez Salgado, al que nombra heredero de sus bienes, y si no tuviese descendencia, a su hermano Domingo Rodríguez Salgado (AHDO, Ourense, Prot. de Luis Fernández, 22 noviembre 1589, fol. 634).

68 AHDO, Ourense, Prot. de Diego Ojea (1588-89), 1589.

${ }^{69}$ AHDO, Ourense, Prot. de Benito González Ojea, 26 junio 1562, fol. 124.

70 AHPO, Ourense, Prot. de Julio Fernández, 4 abril 1569, fol. 59.

71 AHDO, Ourense, Prot. de Gregorio Rodríguez, 1604, fol. 922.
} 
Valdeorras, Quiroga, Castro Caldelas y otras jurisdicciones ubicadas en los lindes de las actuales provincias de Ourense y Lugo ${ }^{72}$. En 1536, el bachiller Olea recoge que "en todas las riberas del Sil e del Miño y en el Condado de Monforte se coge e labra mucha seda", y el Lcdo Molina en su Descripción del Reino de Galicia, (Mondoñedo, 1551), dice que en la comarca lucense se "labra mucha seda y buena"73. Todavía en el último tercio del siglo se comprueba esta producción y su manufactura, pues en las respuestas del Reino al interrogatorio de Felipe II para la repartición de los moriscos granadinos, de 1571, se destaca como una de las singularidades de la villa de Monforte, la existencia de tejedores de seda, "gentes que la crían y se hace terciopelo y otras sedas" ${ }^{\text {". }}$.

La crianza de gusanos y el hilado de sus capullos alimentó una actividad económica en la villa de Monforte, en torno a la que gravitaba toda una serie de pequeños obradores dedicados a torcer la seda, devanarla, teñirla y tejerla. En el periodo de estudio, dicha actividad se presenta dentro de unos límites moderados, a pequeña escala. Cada maestro tejedor contaría con un telar en su domicilio para laborar sus tejidos con la asistencia de algún oficial que le ayudaría en el proceso de hilatura y torcedura de la fibra, labor que a menudo recaía en manos de mujeres ${ }^{75}$. Muy expresivo en este sentido es el concierto de aprendizaje firmado en 1582, entre el sedero Esteban Martiño, vecino de Monforte, con Martiño de Matamá, del lugar de Matamá, para que una hija suya, de nombre Isabel, viviera y estuviera a su servicio, aprendiendo a hacer seda por espacio de cuatro años, debiendo de vestirla y calzarla su padre, y mantenerla el primero, dándole cama, y dejándole enseñado a "fiar" la seda y torcerla, excepto tejer ${ }^{76}$.

Los mercaderes de la villa -caso de los Gaibor, conocida familia de judeoconversos, profundamente enraizada en la sociedad monfortina-, les encargaban sus productos, manteniendo estrechos contactos comerciales con Ourense. Así se comprueba en el poder que en 1573 dio Francisco de Gaibor, vecino de Monforte, al boticario ourensano Antonio López, para pedir al sedero monfortino Francisco de Castroseiros, diez varas de terciopelo de pelo y medio que le había mandado hacer; por no haberlo hecho tan bueno y de tanta seda y color como estaba obligado,

\footnotetext{
${ }_{72}$ V., Antonio Meijide PARdo, "Algunos recursos de Galicia: cáñamo y seda", Revista de Economía de Galicia, 43-44 (1965), págs. 65-78.

${ }^{73}$ Hortensio Sobrado Correa, "Economía rural y vida campesina en la Galicia oriental en tiempos de Carlos V", en Eiras Roel, Antonio (coord.), El Reino de Galicia en la época del emperador Carlos V, Santiago de Compostela, Xunta de Galicia, 2000, pág. 238.

74 María del Carmen GonzÁlez Muñoz, Galicia en 1571: población y economía, A Coruña-Sada, Eds. do Castro, 1982, pág. 210.

75 V., Ana María Ágreda Pino, "El trabajo de la mujer en los obradores de bordados zaragozanos", Artigrama, 14 (2000), págs. 293-312.

${ }^{76}$ AHPO, San Martín de Anllo. Jurisdicción de Monforte, Prot. de Bartolomé Gómez, 11 julio 1582, fol. 146 .
} 
pedía que le devolviese los dineros que le llevó o que deshiciera el engaño. Para ello nombraban sederos que viesen la falta y hacer los autos necesarios, figurando entre los testigos el sedero de Ourense, Francisco Rodríguez ${ }^{77}$.

En otra escritura, de 1578, el mismo tejedor de terciopelo, estante en Ourense, reconoce haber recibido de Francisco de Valcárcel, vecino de la ciudad, cuarenta onzas y media de seda delgada y madeja hilada para tejerla y veintiséis onzas y media de seda macho; y del secretario Rodrigo Martínez, ochenta y tres onzas de seda fina y delgada y treinta y seis onzas de seda macho, también para tejer. Recibiría por cada libra de seda de dieciséis onzas, un ducado por teñir y torcer para tejer, y por tejerla 4 reales por vara, siendo el terciopelo de buena tinta y bien tejido, a vista de Francisco Rodríguez, tejedor de terciopelo, vecino de Ourense. También le darían por cada dieciséis onzas de seda, una de "descabo y desfallo"78.

A su vez, los mercaderes afincados en Ourense establecieron un sistema de trabajo, conocido como "industria a domicilio" o verlagssystem ${ }^{79}$, con el que muchas de las familias campesinas de este valle encontraron una ocupación complementaria que les permitió completar las fuentes de subsistencia.

La fórmula más común era la cesión de la materia prima a los tejedores para que la tejiesen en sus domicilios. De forma que buena parte de los vecinos de las feligresías del coto de Sober: San Martiño de Anllo, San Martiño de Arroxo, Santa María de Proendos, Santo Estevo de Refoxo y San Miguel de Rosende tejían terciopelo en sus propios telares, de forma asalariada.

Su trabajo quedaba asegurado con la firma de una escritura de obligación, en la que quedaba constancia del valor total de la operación y fechas de entrega. Pasado el tiempo estipulado, el tejedor entregaba su producto, o más frecuentemente, el mercader acudía a su domicilio a recogerlo, ya manufacturado, remunerando su importe, proveyéndole, seguramente, de la seda necesaria para la elaboración de nuevos géneros. De esta forma los mercaderes ejercieron un auténtico monopolio, controlando todo el proceso de la producción, desde el suministro de la seda en bruto, a la recogida de la mercancía ya labrada, que después comercializaban en el mercado local, bien directamente en sus tiendas o en las ferias que se celebraban periódicamente.

\footnotetext{
77 AHPO, Ourense, Prot. de Juan Fernández de Luaces, 11 junio 1573, fols. 146, 157.

78 AHPO, Ourense, Prot. de Blas Rodríguez, 22 enero 1578, fol. 31.

${ }^{79}$ La expansión de la industria sedera tuvo un incremento de su producción por la extensión de este sistema de trabajo, con gran desarrollo en las regiones y ciudades españolas de rica tradición artesanal. V., María Ángela JimÉnEz MonTAÑés, "La regulación del sistema productivo de la industria textil en el siglo XVI en Toledo: una aproximación", en VII Encuentro de Trabajos sobre la Historia de la Contabilidad, León, Universidad de León, 2010, págs.1-22; íd., "La industria textil y su regulación en el siglo XVI: caso particular de Toledo", Pecnia. Revista de la Facultad de Ciencias Económicas y Empresariales, 14 (2012), págs. 107-132; Ángel SAntos VAquero, La industria textil sedera de Toledo, Cuenca, Ediciones de la Universidad de Castilla-La Mancha, 2010, pág. 87.
} 
Cada mercader disponía de uno o dos tejedores a su servicio, lo que indica un modesto ritmo de producción, siendo siempre el género el del terciopelo de un pelo, la técnica más simple, y el color de su tintura el negro, idóneo tanto para el vestido como para paños mortuorios o cubiertas de ataúdes.

Para el mercader Manuel de Mena trabajó el sedero Bartolomé Rodríguez, vecino de San Miguel de Rosende, según se desprende de una escritura suscrita en 1564, por la que se obligaba a darle veinticuatro varas de terciopelo negro de buena tinta de dar y de tomar, desde Monforte, a vista de oficiales, por razón de 480 reales $^{80}$.

Andrés Rodríguez de Soto, sedero del lugar de Sober, trabajó durante largos años para el rico mercader Leonardo de Mena. En 1572 reconoce deberle cuarenta varas de terciopelo negro de un pelo, por razón de 80 ducados menos 20 reales que había recibido de Simón de Mena, su hijo. En el mismo día, se obliga a pagar a Leonardo de Mena, cincuenta y una varas de terciopelo negro de un pelo, bueno de dar y tomar, para el mes de agosto y Navidad ${ }^{81}$. En 1573 actúa como fiador de Gonzalo Gutiérrez, vecino de Monforte, en una obligación de 60 dudados con Leonardo de Mena, por veinte varas de terciopelo negro "que ha de ser muy bueno, de un pelo, y bien tejido e negror"; un mes después se compromete a dar al mercader cuarenta varas de terciopelo negro, "de buena seda y negror" por 80 ducados, la mitad para el día de Nuestra Señora de septiembre y el resto para Navidad $^{82}$. En 1574 se obliga a tejer noventa varas de terciopelo, de buen pelo, que le entregaría para el día de San Martiño ${ }^{83}$. En 1579, Andrés Rodríguez se compromete a dar a Leonardo de Mena cincuenta y cinco varas de terciopelo de un pelo que sea bueno y de buen color, a 20 reales la vara, para principios de septiembre $^{84}$. Un año después da carta de pago de 800 reales por cuarenta varas de terciopelo de un pelo, "bueno e de buen negro de dar y de tomar" a Leonardo de Mena, a precio de 20 reales cada vara ${ }^{85}$. Y en 1586, se obliga a pagar al mercader cinco varas de terciopelo negro de un pelo, bueno y bien obrado ${ }^{86}$.

Todo indica que tras el fallecimiento de Leonardo de Mena, Andrés Rodríguez pasa a trabajar para su hermano Lope de Mena, pues en 1592, se obliga a entregar "texidas y proporcionadas" ochenta y cinco varas de terciopelo negro de un pelo "de buen negror que sea bien texido de dar y tomar y limpio" a Lope de Mena o a quien su poder tuviere, en el lugar de Sober, a precio de 23 reales la vara ${ }^{87}$.

\footnotetext{
${ }^{80}$ AHDO, Ourense, Prot. de Jácome de Faro, 1564, fol. 357.

${ }^{81}$ AHPO, Ourense, Prot. de Juan Soto, 9 junio 1572, fols. 245, 246.

82 AHDO, Ourense, Prot. de Gómez Cid, 24 mayo 1573, fol. 517; 8 Junio 1573.

83 AHPO, Ourense, Prot. de Gómez Cid, 15 mayo 1574, fol. 1449.

${ }^{84}$ AHDO, Ourense, Prot. de Pedro Feixoo, 9 junio 1579, fol. 394.

85 AHDO, Ourense, Prot. de Francisco García, 3 junio 1580, fol. 462.

${ }^{86}$ AHDO, Ourense, Prot. de Francisco García, 1586, fol. 627.

87 AHDO, Ourense, Prot. de Luis Fernández, 17 junio 1592, fol. 489.
} 
A la muerte de Lope de Mena, Andrés Rodríguez hace cuentas con Cristóbal de Buendía, casado con su viuda, como muestra una escritura, de 1595, por la que se obligaba a darle cincuenta y seis varas de terciopelo; treinta y seis varas correspondían a lo que había restado debiendo a Lope de Mena, difunto, marido que fue de Elena Núñez, mujer que al presente era del dicho Cristóbal, y las veinte restantes a cumplimento de las que éste compró y pagó a precio de 23 reales cada vara.

Las posibilidades que ofrecía Ourense para el trabajo de la seda justifica el traslado de algunos talleres al espacio urbano. Sobre este particular consta la petición, en 1549, de Pedro González al Consistorio, porque quería venir a hacer sedas en Ourense, para que la ciudad "se aumente en paños". Los regidores lo recibieron por vecino pagando alcabala de todo lo que comprase y vendiese en lo tocante al oficio de sedero, dándole las casas de la Carnicería en que al presente vivía el carpintero Pedro González, por un año ${ }^{88}$. Pasado el tiempo regresaría a Sober, pues en 1576 figura como vecino de la feligresía de Refoxos, obligándose a pagar a Leonor Enríquez, viuda de Lisuarte de Mena, 80 ducados que le prestó y "cuarenta y ocho varas en terciopelo negro bueno que hace en su oficio", a precio de 20 reales la vara ${ }^{89}$.

Otro sedero de este coto, Pero Rodríguez, se obliga en 1566 a entregar a cada uno de los mercaderes Leonardo de Mena, Lope de Buendía y Juan Gómez, sesenta varas de terciopelo negro, de un pelo, a precio de 20 reales la vara, "bueno de dar y tomar" ${ }^{\prime 90}$. En 1575 ya había fallecido, pues en este año su viuda, Catalina Vázquez, se obliga a entregar al mercader Juan Gómez sesenta y una varas y media de terciopelo negro, por 65 ducados $^{91}$.

Para el mercader Francisco Enríquez trabajó el sedero Luis Vázquez, vecino de Santa María de Proendos, pues en el año 1564 se obliga a darle cuarenta varas de terciopelo negro de un pelo que le había de entregar en dicho coto de Sober, a precio de 17 reales la vara ${ }^{92}$. En 1570 se obliga a tejerle veintiocho varas de terciopelo negro "que sea bueno de dar y de tomar", a precio de 19 reales la vara ${ }^{93}$. En 1573, veintidós varas de terciopelo, dando por su fiador al sedero Pedro González $^{94}$. Y en 1578, confiesa haber recibido de Francisco Enríquez, 10 ducados a cumplimiento de los 40 que le había dado por veintidós varas de terciopelo que estaba obligado a darle, según obligación otorgada entre ambos ${ }^{95}$. Finalmente, se

\footnotetext{
${ }_{88}$ AHPO, Ayuntamiento Ourense. Libro de Acuerdos, 10 mayo 1549.

89 AHPO, Ourense, Prot. de Juan Soto, 12 junio 1575, fol. 207.

90 AHDO, Ourense, Prot. de Jácome de Faro, 19 mayo 1566, fol. 342.

91 AHDO, Ourense, Prot. de Gómez Cid, 1575.

92 AHDO, Ourense, Prot. de Jácome de Faro, 17 abril 1564, fol. 296.

93 AHDO, Ourense, Prot. de Francisco García, 8 Junio 1570, fol. 652.

94 AHPO, Ourense, Prot. de Juan Soto (1571-1574), 15 junio 1573.

95 AHDO, Ourense, Prot. de Francisco García, 10 junio 1578, fol. 201.
} 
obliga, en junio de 1584, a entregar al mercader treinta y tres varas de terciopelo negro "del de Monforte", bueno de dar y tomar, de un pelo, puesta la mitad en Ourense hasta el 7 de agosto y la otra mitad hasta el 12 de octubre, a precio de 2 ducados la vara ${ }^{96}$.

Para Manuel López de Morais trabajó el sedero Juan Fernández, vecino de la feligresía de Santa María de Proendos. En 1565 consta un pago al mercader de 115 reales y medio que le había prestado ${ }^{97}$. En el mismo año se compromete a darle veinticuatro varas de terciopelo negro de buena tinta, por 480 reales, a razón de 20 reales la vara ${ }^{98}$. Cuatro años después, Juan Fernández se obliga a dar a Cristóbal de Buendía treinta varas de terciopelo negro, bueno y de buen negro, a vista de oficiales, que el dicho Cristóbal le había comprado a precio de 19 reales la vara ${ }^{99}$.

Otro sedero de esta misma feligresía, Lorenzo Carneiro, confiesa, en 1572, haber recibido de Gracia de Fonseca, mujer del mercader Leonardo de Mena, 50 ducados menos 2 reales, por veinticinco varas y media de terciopelo negro "que sea de dar y tomar", entregando la mitad en agosto y el resto para Navidad, bajo pena de que si no cumpliese el plazo pueda comprar otro terciopelo pagándolo a su costa ${ }^{100}$. En 1573 se compromete a dar al mismo mercader treinta varas de terciopelo negro, “de muy buena seda e negror", por 60 ducados ${ }^{101}$. A comienzos del año 1575, Carneiro, como principal, y el sedero Pedro González, como su fiador, se obligan a pagar al mercader Juan Gómez, diez varas de terciopelo negro, bien tejido y de buen espesor, por razón de lo cual le había pagado 20 ducados ${ }^{102}$. Y en 1580, Lorenzo Carneiro da carta de pago al mercero Miguel Rodríguez de veinticinco varas de terciopelo negro de un pelo, bueno de dar y tomar, a 24 reales cada vara, por 600 reales $^{103}$.

Finalmente, consta que el sedero Cristóbal Rodríguez, del coto de Sober, trabajó para Marcelo de Mena, según se comprueba de una escritura de 1571, por la que se obligaba a darle cuarenta y cinco varas de terciopelo negro, de un pelo, "que sea bueno de dar e tomar medido por la vara castellana que agora se usa", las cuales se las había comprado por 900 reales, que cobró en moneda y paños de su tienda ${ }^{104}$.

\footnotetext{
96 AHDO, Ourense, Prot. de Gaspar Salgado, 22 junio 1584.

97 AHDO, Ourense, Prot. de Jácome de Faro, 1565, fol. 305.

98 AHDO, Ourense, Prot. de Jácome de Faro, 1565, fol. 315 v.

99 AHDO, Ourense, Prot. de Jácome de Faro, 1569, fol. 393.

${ }^{100}$ AHPO, Ourense, Prot. de Juan Soto, 13 junio 1572, fol. 242.

${ }^{101}$ AHDO, Ourense, Prot. de Gómez Cid, 8 Junio 1573.

${ }^{102}$ AHDO, Ourense, Prot. de Gómez Cid, 7 febrero1575.

${ }^{103}$ AHDO, Ourense, Prot. de Francisco García, 6 enero 1580, fol. 436.

${ }^{104}$ AHDO, Ourense, Prot. de Juan Sotelo, 9 agosto 1571, fol. 10.
} 


\section{BORDADORES}

La creciente demanda de tejidos bordados por clientes particulares, pero, sobre todo, el encargo de ornamentos y vestimentas religiosas por los distintos miembros del clero diocesano, incentivó el trabajo del bordado en las décadas centrales del siglo XVI. Con anterioridad, no existe certeza del asentamiento permanente de bordadores en la ciudad de Ourense, teniéndose que recurrir a maestros de otros lugares o a artistas itinerantes que iban de una población a otra en busca de ocasionales trabajos. Es el caso de Jaime de Candaygla o Jaimes Candala, broslador vecino de Vitoria, que el 29 de noviembre de 1547 daba a Juan Bautista, armero, y a Sebastián de Salinilla, tundidor, estantes en Ourense, un retablo del Testamento Viejo y parte del Nuevo, con todos sus aparejos para que lo usasen en los lugares que quisieren durante un año, con la condición de que le dieran la tercera parte de lo que ganasen. Esperarían con el retablo en la ciudad de Salamanca hasta el día de Pascua de Flores ${ }^{105}$. Pero este retablo, trabajado con escenas historiadas y destinado para su uso o exhibición en festividades religiosas, no deja de ser una obra ocasional, que no dependía directamente de la clientela local.

Fueron las instituciones religiosas y las clases adineradas las principales demandantes de tejidos bordados. De los procedentes del ámbito doméstico y de los que formaron parte del vestido y accesorio personal, apenas han llegado a nosotros, al ser especialmente vulnerables por su frecuente uso y continuo reciclaje. Pero las dotes e inventarios postmortem de las personas pudientes reflejan bien sus refinados gustos, siguiendo los imperativos de la moda, pasando de generación en generación por legados testamentarios o siendo objeto de un activo mercado de segunda mano. Tampoco muchos de los bordados usados en el ceremonial religioso han sobrevivido, pues los conservados en sacristías y museos apenas si representan una muestra muy parcial de los ajuares litúrgicos.

A pesar del interés y del valor artístico de muchas de estas piezas, son escasas las investigaciones realizadas, pues, a excepción de Santiago de Compostela ${ }^{106}$, foco de fabricación de bordados al más alto nivel regional, se carece de cualquier dato acerca de las personas que los ejecutaron. Las fuentes notariales, no obstante, contienen cumplida información sobre promotores y artistas, con minuciosas claúsulas especificando sus características formales, iconográficas, plazos de ejecución, precio y formas de pago.

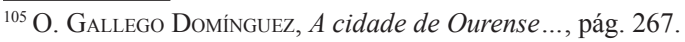

${ }^{106}$ V., Pablo Pérez Costanti, "El arte en Galicia. Pintura a la aguja. Brosladores de los siglos XVI y XVII", en Notas Viejas Galicianas, II, Vigo, s. n., 1925, págs. 337-342; Pilar Benito García, "La colección de ornamentos litúrgicos de la catedral compostelana", en Santiago. La Esperanza, vol. 2, Santiago, Xunta de Galicia, 1993, págs. 171-178; Jesús Aguilar Díaz, "El arte del bordado en Santiago de Compostela. Nuevos datos sobre bordadores de los siglos XVI y XVII", Cuadernos de Estudios Gallegos, LVIII, núm. 124 (2011), págs. 183-196.
} 
La Iglesia fue la mayor beneficiaria del arte del bordado. Desde obras confeccionadas con ocasión de señaladas ceremonias, a prendas procedentes de mandas testamentarias para las parroquias donde los clérigos ejercían su ministerio o encargadas por particulares para las capillas funerarias de los templos de su devoción. Pero además eran un elemento de gran importancia para solemnizar el culto. Al amparo de las instrucciones tridentinas, los visitadores diocesanos daban órdenes periódicamente para que se encargase todo tipo de vestiduras y ornamentos para el servicio de los oficios, lo que propició la llegada de profesionales para su producción.

Son los clientes quienes determinaban los temas o asuntos que habrían de decorar las piezas bordadas, de acuerdo a las advocaciones y devociones de los patrocinadores, dominando las escenas marianas y series de santos con el titular de la parroquia a la cabeza. Los repertorios reflejan bien la evolución de las formas estéticas del renacimiento, desde la decoración "al romano" a ornamentaciones basadas en elementos arquitectónicos con la imaginería contenida dentro de tabernáculos y capillas, llamadas "portadas". Y como sucede en otras parcelas artísticas, era habitual la exigencia de que la obra se ajustase al modelo de piezas hechas para otros lugares o existentes en la propia iglesia, así como la existencia de dibujos o trazas previas, con cuyo procedimiento se aseguraba la fidelidad del bordador según las pautas concertadas.

Los comitentes intentaban asegurarse de que la calidad de los hilos con que se bordaban los motivos fuesen de la calidad necesaria para realzar la riqueza y vistosidad de las prendas, lo que exigía habilidad en el manejo de la aguja para plasmar los efectos de volumen y claroscuro propios de una representación naturalista. Acostumbraban a hacerse con sedas de diferentes colores, preferentemente de Granada, muy usada en el periodo de estudio para las ropas litúrgicas, y con hilos metálicos, particularmente la plata y el "oro fino" de la mejor clase, o "de Milán", compuesto por un alma de seda cubierta por una fina lámina de plata dorada. Normalmente se fijaba de antemano el precio que había de alcanzar la obra terminada, aunque también se acudía al sistema de tasación, por el que su precio quedaba condicionado a la valoración de reconocidas personas que certificaban su calidad o por otros profesionales de la aguja.

La falta de mano de obra justificó que fueran requeridos los servicios de los más prestigiosos bordadores compostelanos. Es el caso de Gonzalo de Luaces (+1575), a quien el Cabildo compostelano dio el oficio de broslador, y que aparece dando un poder para cobrar del mercader ourensano Antonio Fernández, 40 reales de plata ${ }^{107}$. En 1571 toma a su cargo hacer para Santa Baia de Banga (O Carballi-

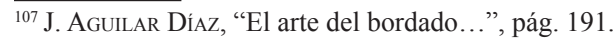


ño), dos dalmáticas, una casulla y tres albas de Roan “y las almáticas, conforme a las de la Abadesa de San Payo, con sus faldones bordados de oro fino y tela de Milán", con tres figuras en la delantera con los apóstoles Santiago, San Juan y San Pedro, y en la trasera, Nuestra Señora, Santa Olaya y Santa Lucía. Las dalmáticas tendrían sus cordones de seda carmesí con redecilla de oro y botones de oro y seda, todo "de muy fina seda y terciopelo carmesí" y el pago se haría a tasación de "los muy magníficos señores cardenal Durana y canónigo Juan Patiño"108.

También en 1609, el bordador compostelano Fernando Álvarez Rebellón recibe el encargo de una casulla de damasco blanco, con cenefa bordada sobre terciopelo carmesí, "perfilada y formada de oro fino de Milán con sus retorchas a los lados de una pulgada de ancho" para Santa Mariña de Augas Santas (Allariz), cuyas labores habían de ser iguales a otra casulla que tenía la iglesia ${ }^{109}$. En 1626, el mismo maestro contrata por 4.510 reales "un terno de tela fina colorada y blanca y oro", forrado de tafetán carmesí con sus pasamanos de oro fino de Milán, para la parroquial de San Miguel de Osmo (Cenlle), que habría de entregar el día del Corpus del mismo año ${ }^{110}$.

No faltan tampoco ocasionales encargos a cualificados bordadores de Valladolid, ciudad con la que Ourense mantuvo fructíferas relaciones artísticas. En 1571, el P. Fr. Francisco de Valencia, monje del monasterio de Belén, contrataba en Valladolid al bordador Fernando de Saldaña la confección de un frontal de tela de plata, para el monasterio de San Clodio. Sería de tres varas de largo y cinco palmos de ancho y en la delantera llevaría tres portadas con cinco querubines ${ }^{111}$ En 1598, Luis de Cea, bordador de la misma ciudad, reconoce haber recibido del canónigo Zárate 12 ducados por la factura de un escudo de armas que mandó hacer el canónigo Novoa y que fue tasado por el bordador Sebastián de Zárate, vecino también de Valladolid ${ }^{112}$. Incluso algunos bordadores castellanos aparecen avecindados en las villas de la provincia, según se comprueba en 1572, en que el Licdo. Vivanco, corregidor de Ourense, da licencia a Domingo do Río el Mozo, vecino de Santa María de Albán, para vender un macho a Antonio de Benavente, "broslador", habitante en la villa de Ribadavia"13.

A partir de la aplicación de los acuerdos del Concilio de Trento y las disposiciones sobre las vestimentas litúrgicas obligatorias, el número de bordadores

\footnotetext{
${ }^{108}$ Antonio López Ferreiro, "Bordados y bordadores de Santiago", Galicia Histórica, 4 (1902), pág. 262; P. Pérez Costanti, "El arte en Galicia. Pintura a la aguja...”, pág. 346; Íd., Diccionario de artistas..., págs. 349-350.

${ }^{109}$ A. López Ferreiro, “Bordados y bordadores...”, págs. 263 y ss.; P. Pérez Costanti, "El arte en Galicia. Pintura a la aguja...”, pág. 356.

${ }^{110}$ P. PÉRez Costanti, "El arte en Galicia. Pintura a la aguja...”, pág. 357.

${ }^{111}$ AHPV, Valladolid. Prot. de Pablo García, 17 agosto 1571, fol. 35.

${ }^{112}$ AHPO, Catedral, Capellanía de las Nieves, I, 7 diciembre 1598, fol. 290.

${ }^{113}$ AHDO, Ourense, Prot. de Gaspar Salgado, 19 marzo 1572, fol. 174.
} 
aumenta considerablemente. A finales de siglo figura Julián Rodríguez, de quien no tenemos otra noticia que la de un poder, de 1585 , de D. Fernando de Mendoza y Caamaño, vecino de Villagarcía, a procuradores de causas en la ciudad, para cierto pleito, por razón de ciertos paños de figuras "que dize no los haber rematado y que después los vendió en otra parte y otras cosas" "114.

También se registra la presencia del bordador Francisco del Castillo. En 1590 contrata una manga de cruz para San Bartolomé de Ganade (Xinzo de Limia) ${ }^{115}$. En 1592 recibe de Baltasar de Castro, mayordomo de la cofradía de Nuestra Señora Santa María la Madre, 12.000 maravedís por "broslar" las insignias del pendón de dicha cofradía, de lo que daba carta de pago ${ }^{116}$. Del mismo conocemos un contrato de aprendizaje suscrito en 1598 con el mercader Antonio Vaz, por el que se comprometía a enseñar el oficio de bordador a Diego Suárez, hijo del maestro Francisco Rodríguez, difunto, en el plazo de cuatro años y medio. El mercader le pagaría por la enseñanza 20 ducados, dando cama para dormir, vestir y calzar al aprendiz durante los dos primeros años, correspondiendo el resto al maestro ${ }^{117}$.

Pérez Costanti da noticia del bordador Miguel Varela, quien en 1608 firma un contrato con Francisco de Castro, mayordomo de la iglesia de Santa María de Codosedo (Sarreaus), para hacer en el mes de mayo, por 42 ducados, una manga de terciopelo de dos pelos de Granada, colorado, bordada de la forma y largo del terciopelo de la iglesia de la Santísima Trinidad de Ourense, llevando a los lados cuatro imágenes guarnecidas, matizadas con seda de matiz sobre raso blanco y ornadas con oro, siendo las de Nuestra Señora de la Asunción con sus ángeles, San Pedro, San Juan y San Ildefonso ${ }^{118}$.

En el mismo año, contrata por 49 ducados, con Marcos da Cruz, procurador de la iglesia de Santa María de Mugares (Toén), la factura de otra manga para la cruz, igual a la de la iglesia de Santa María de Toén "que el dho Miguel Varela fue a ver". Sería de terciopelo carmesí de Granada, y en los campos llevaría cuatro hechuras "peleteadas" con sus viseras de torzal de oro. Las figuras, del alto de una tercia, serían: Nuestra Señora de la Asunción con cuatro ángeles, Santa Marina con su dragón, San Martín obispo y San Pedro ${ }^{119}$.

En 1611, Miguel Varela firma un contrato con Esteban Yáñez, abad de Santiago de Allariz, para hacer una manga para la cruz de dicha iglesia según las condiciones

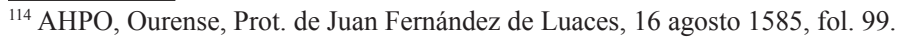

${ }^{115}$ AHDO, Ourense, Prot. de Juan Serrano, 23 octubre 1590, fol. 840.

${ }^{116}$ AHDO, Ourense, Prot. de Luis Fernández, 23 abril 1592, fol. 409.

${ }^{117}$ AHPO, Ourense, Prot. de Antonio Fernández, 22 junio 1598, fol. 167. P. PÉrez Costanti, "El arte en Galicia. Pintura a la aguja...", pág. 366.

${ }^{118}$ AHPO, Ourense, Prot. de Pedro de Lemos, 18 marzo 1608, fol. 846. P. PÉrez Costanti, "El arte en Galicia. Pintura a la aguja...”, pág. 366; P. Pérez Costanti, Diccionario de artistas..., pág. 537.

${ }^{119}$ AHDO, Ourense, Prot. de Alonso Vázquez Ojea, 29 marzo 1608, fol. 856. P. Pérez Costanti, Diccionario de artistas..., pág. 538.
} 
siguientes: el campo de la manga con la coronación sería de terciopelo carmesí de dos pelos de Granada, "que sea muy bueno". Llevaría cuatro portadas con sus pilares y arcos, y en medio de cada arco un paño colgado con un serafín. Por encima de los arcos, "sus romanos" con hojas todo alrededor. Encima de cada remate de pilar, conforme a la muestra que le mostró Varela, irían las hojas que tiene la traza; en las puntas de la coronación han de ir otros "romanos" pequeños con sus hojas, y en el campo que quedase una venera con estrellas alrededor y un bordón o dos en cruz. Por debajo de las peanas de los pilares y alrededor de la manga, otro "romano" con hojas de diferente hechura de los de arriba. En cada portada llevaría una figura de la Concepción de Nuestra Señora con los pies sobre la luna y un serafín debajo, el apóstol Santiago, San Sebastián y San Roque con sus insignias y ropas de diferente hechura y colores. Se le pagarían 90 ducados, y estaría hecha el 1 de noviembre de 1611.

En 1613 contrata otra manga de cruz para la iglesia de San Salvador de Riofreixo (Sarreaus), de la forma "y tan acabada como la de la cruz de Codosedo", excepto que las figuras serían las de San Salvador, Nuestra Señora del Rosario, San Ildefonso y San Juan Bautista. Por su hechura recibiría 13 ducados y medio, "mas diez y seis reales de la seda que ha de poner de los matices para las imágenes, y dos ducados al cordonero que hiciese los cordones". Daba por fiador a su convecino, el pintor Gonzalo Pérez ${ }^{120}$.

Finalmente, en 1636, Domingo Álvarez, mayordomo de la iglesia de Santa María de Cartelle, se conviene con Juan Fernández, bordador de Ourense, para hacer un terno de casulla para diácono y subdiácono, de damasco blanco el cuerpo y lo demás de damasco colorado, en 300 reales, para vísperas de Nuestra Señora de septiembre ${ }^{121}$. Dos años después, el mayordomo confesaba haber recibido el terno de damasco blanco con cenefas coloradas y con sus franjas en todas las costuras de seda blanca y colorada.

\section{Casulleros}

Dentro de los trabajos textiles, los había especializados, como los casulleros, dedicados a la ejecución y montaje de las ropas litúrgicas, que no siempre llevaban labores de bordado, por lo que su oficio aparece de forma diferenciada del de los bordadores.

Entre ellos tenemos noticia de Francisco González. Siguió en el oficio su hijo Antonio. En 1633, María de Trelle, soltera, de más de 18 años, natural de Mugares y moradora en Ourense, que había servido algunos años a Antonio

\footnotetext{
${ }^{120}$ AHDO, Ourense, Prot. de Gregorio López de Cárdenas, 19 Abril 1613, fol. 486. Pablo Pérez Costanti, Diccionario de artistas..., pág. 538.

${ }^{121}$ AHPO, Ourense, Prot. de Juan de Espinosa, 5 abril 1636 (con firma autógrafa del bordador).
} 
González "casullero", y había tenido una criatura suya, pretendía ponerle pleito por la soldada y deshonra, concertándose finalmente con el sobredicho en que le pague 3 ducados al contado, recibiese la criatura y la diese a criar y cuidase de ella en adelante ${ }^{122}$.

En 1646, su hermano Francisco González Seoane de Rivera, vecino de la villa de Cambre, vende a Juan Álvarez de Hermida, medio lagar de piedra, medio pilo y la mitad de una casa en la canella de Penavixía que demarcaba con los lagares de D. Hernando de Deza y Andrade y con la huerta de D. Antonio Taboada, según las había heredado de sus padres Francisco González, casullero, y Lucía Rodríguez ${ }^{123}$. Meses después, el casullero Antonio González vende a su hermano, barbero y cirujano, vecino de Santa María de Cambre, el medio lagar de piedra y la mitad de la casa que le había correspondido en partijas ${ }^{124}$.

\section{CORdONEROS Y PASAMANEROS}

A los maestros anteriores se añade la actividad de otros profesionales a los que se requería para los accesorios textiles, que en muchos casos constituían realizaciones de interés dada la variedad de galones, trencillas, cintas, cordones, borlas, flecos, guarniciones y demás adornos de oro y plata, que complementaban las prendas litúrgicas.

Entre los cordoneros tenemos noticia de Gaspar López, quien en 1568 da poder a procuradores en la Real Audiencia para un pleito que trataba con el también cordonero Juan de Bilbao, estante en la ciudad, "sobre ciertas palabras que me dixo" ${ }^{25}$. En 1588, Juan Fernández Penedo, clérigo de San Martiño de Laiosa (Incio), le paga 25 ducados por una casulla, estola y manípulo de carmesí colorado "con sus franxas de oro fino de Milán con una çenefa de brocatel" que le vendió en dicho precio $^{126}$. Y en 1601, Estebo de Monte, mayordomo de la iglesia de San Tomé de Barxa (Celanova), se concierta con el cordonero para hacer una casulla de damasco colorado con su cenefa, alba y manípulo, por 24 ducados ${ }^{127}$.

En 1574 figura el cordonero Francisco de Rosendo junto a su mujer, Florenza González, dando poder a procuradores para un pleito con el mercader Álvaro de Mena, vecino de la villa de Villalpando, sobre 16 ducados que le pedían ${ }^{128}$. Otro

\footnotetext{
${ }^{122}$ AHPO, Camino de Ourense a San Ciprián, Prot. de Juan de Espinosa, 5 agosto 1633.

${ }^{123}$ AHPO, Marqués de Leis. Casa de la Canella de Penavixía, 26 julio 1646.

${ }^{124}$ AHPO, Marqués de Leis. Casa de la Canella de Penavixía, 28 enero 1647.

${ }^{125}$ AHPO, Ourense, Prot. de Gómez Cid, 28 octubre 1568, fol. 264. Juan de Bilbao era vecino de Monforte de Lemos, según consta en una carta de obligación con el mercader Domingo González, de 1588 (AHDO, Ourense, Prot. de Juan Serrano, 8 agosto 1588).

${ }^{126}$ AHDO, Ourense, Prot. de Juan Sotelo, 9 mayo 1588, fol. 160.

${ }^{127}$ AHDO, Ourense, Prot. de Juan Sotelo, 9 mayo 1601.

${ }^{128}$ AHDO, Ourense, Prot. de Gómez Cid, 14 Junio 1574, fol. 135.
} 
cordonero, Bartolomé López, aparece en 1579 en un pleito de los de este oficio con los sombrereros de la ciudad ${ }^{129}$. En 1588, el cordonero Juan López de Lira, da carta de pago al sedero Francisco Rodríguez y a Juan Montoya, de 25 ducados por dos moyos de vino tinto que estaba obligado a pagar cada año de fuero a los herederos de Mendo de Puga, de los que eran arrendadores ${ }^{130}$. Y el cordonero Jerónimo Fernández, hijo de Gregorio Fernández y de María de Castro, aparece por las mismas fechas dando un poder para demandar ${ }^{131}$.

Ya a comienzos del XVII figura el cordonero Gregorio Alonso, del que conocemos un contrato de aprendizaje, de 1602, con el sombrerero Bastián de Ribeira, para enseñar el oficio a su hijo, Domingo de Ribeira, de 17 años de edad, por tres años, que se sumaban a otros dos que le había tenido en su casa, sin darle por razón de ello cosa alguna, puesto "que se le pone por más tiempo de lo que es costumbre" 132 . Otro cordonero de este momento, Bernardo de los Huertos, siendo mayordomo de la cofradía de Santa María Madre, se concierta en 1606 con el pintor Gonzalo Pérez para pintar y dorar la imagen de Nuestra Señora, de la cofradía, sita en la iglesia, con sus cuatro ángeles, dos de la corona y dos que llevan dos candeleros, y las demás historias a espaldas y a los lados. Todo ello "bien pintado y dorado al olio", siendo las encarnaciones de los rostros a pulimento, aplicando sobre el oro colores finos como carmín, verde, azul, y blanco en camisas y tocas. Lo entregaría para el día de Pascua de Resurrección, a vista de oficiales, para la procesión de la mañana, por 500 reales en dos pagas. Figuran como testigos los cordoneros Gregorio Alonso y Pedro de Rosende ${ }^{133}$. En 1619, Bernardo dio de limosna para la obra de la ermita de la Virgen del Posío, 100 reales que por mandato de la Justicia y Regimiento había prestado para la obra y edificio de la Porta da Aira y que aún no se le habían devuelto ${ }^{134}$.

Finalmente, en 1609 Antonio Feijoo, abad de Santa María de Podentes (A Bola), firma un contrato con el cordonero Gonzalo Ribero, de Ourense, para la factura de unos cordones de seda "de almática" para la cofradía de Nuestra Señora del Rosario, iguales a los de la iglesia de la Trinidad, excepto que no llevarían oro alguno, por 20 ducados por la seda y la hechura ${ }^{135}$.

Entre los pasamaneros cabe citar a Esteban Álvarez, del que en 1616 consta un poder a favor de Pedro Mosquera de Toubes, procurador de Ourense, para cierto

\footnotetext{
${ }^{129}$ AHDO, Ourense, Prot. de Luis Fernández, 17 Diciembre 1579.

${ }^{130}$ AHDO, Ourense, Prot. de Juan Sotelo, 27 marzo 1588, fol. 182.

${ }^{131}$ AHDO, Ourense, Prot. de Francisco García, 1590, fol. 35.

${ }^{132}$ AHPO, Ourense, Prot. de Pedro de Lemos, 17 enero 1602, fol. 593.

${ }^{133}$ AHDO, Ourense, Prot. de Juan de Neboeiro, 8 enero 1606, fol. 630.

${ }^{134}$ O. Gallego Domínguez, "Torres, puertas y cerca...”, pág. 268; O. Gallego Domínguez, A cidade de Ourense..., pág. 48.

${ }^{135}$ AHPO, Orense, Prot. de Alonso Vázquez Ojea, 24 diciembre 1609, fol. 693.
} 
pleito que trataba con el oficio de la Justicia y con Lucía de Castro, vecina de la ciudad, sobre una querella en la que se declaraba sin culpa ${ }^{136}$.

\section{CONCLUSIONES}

Como en numerosas poblaciones y ciudades menores, en Ourense, uno de los sectores de la industria al que correspondió un mayor protagonismo en el siglo XVI, fue el textil, surgido tanto a expensas de la necesidad como del lujo. El considerable número de mercaderes de paños y de tejedores asentados en la ciudad para atender las necesidades de consumo generadas entre la población, desempeñó un papel sustancial en el desarrollo y modernización de la economía urbana, aunque por su modestia resultase insuficiente para activar un proceso de industrialización a mayor escala.

Más allá de la expansión de los telares por el mundo rural, como una actividad estrictamente familiar, el abastecimiento de textiles se servía tanto del comercio exterior como de la manufactura local, generalmente en manos de artesanos de procedencia foránea. Frente a la modestia de sus productos -lienzos, estopas y paños- otros campos textiles, como los tejidos labrados y bordados, confeccionados principalmente para las prendas litúrgicas y ornamentos utilizados en el ceremonial religioso, alcanzaron un notable florecimiento y calidad artística, según consta de las fuentes analizadas, abriendo nuevos campos a profesionales dedicados a este trabajo, como bordadores, cordoneros o pasamaneros. La escasez de piezas conservadas, que apenas representan una muestra muy parcial de las existentes en su momento, hace que resulten particularmente clarificadoras las noticias y referencias documentales con las que contamos.

En el mismo espacio temporal, la creciente demanda de tejidos lujosos generada por las clases altas de la sociedad, favoreció el desarrollo de un sistema de producción alternativo, conocido como verlagsystem, basado en la utilización de mano de obra campesina, ubicada en regiones rurales productoras, caso de la zona de Monforte (Lugo), donde una serie de familias dedicaban sus horas libres al trabajo de tejer terciopelo de seda negro, como una actividad complementaria a las labores del campo, obteniendo unos ingresos que ayudaban al incremento del presupuesto familiar. El centro de planificación de esta producción a domicilio residía en la ciudad de Ourense, donde los mercaderes controlaban el sistema productivo en toda su extensión, desde facilitar a los talleres la materia prima necesaria, a recoger los productos una vez elaborados para destinarlos al consumo mediante sus canales habituales de distribución y venta.

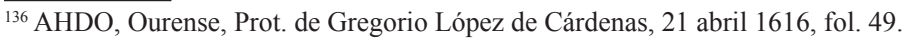




\section{BIBLIOGRAFÍA}

Ágreda Pino, Ana María, "El trabajo de la mujer en los obradores de bordados zaragozanos", Artigrama, 14 (2000), págs. 293-312.

Aguilar Díaz, Jesús, "El arte del bordado en Santiago de Compostela. Nuevos datos sobre bordadores de los siglos XVI y XVII", Cuadernos de Estudios Gallegos, LVIII, núm. 124 (2011), págs. 183-196.

Barriocanal López, Yolanda, La actividad escultórica en Ourense, del Renacimiento al Barroco, Ourense, Consejo Superior de Investigaciones Científicas. Grupo Marcelo Macías, 2016.

Benito García, Pilar, "La colección de ornamentos litúrgicos de la catedral compostelana", en Santiago. La Esperanza, vol. 2, Santiago, Xunta de Galicia, 1993, págs. 171-178.

Carmona Badía, Joám, El atraso industrial de Galicia. Auge y liquidación de las manufacturas textiles (1750-1900), Barcelona, Ariel, 1990.

Gallego Domínguez, Olga, "Torres, puertas y cerca de la ciudad de Orense”, Boletín Auriense, II (1972), págs. 241-278.

Gallego Domínguez, Olga, A cidade de Ourense. Unha visión a través dos séculos, Ourense, Museo Arqueolóxico Provincial de Ourense, 2001 (Boletín Auriense. Anexo 27).

Gallego Domínguez, Olga, Historia da muller. Mulleres ourensás dos séculos XIV-XVIII, Ourense, Grupo Marcelo Macías, 2008.

Gelabert González, Juan Eloy, Santiago y la tierra de Santiago de 1500 a 1640. (Contribución a la historia económica y social de los territorios de la Corona de Castilla en los siglos XVI y XVII), Sada. A Coruña, Ed. do Castro, 1982, pp. 242-248.

González García, Miguel Ángel, "Unas ordenanzas de la cofradía orensana de Santa María Madre, del siglo XVI", Boletín de Estudios del Seminario “Fontán-Sarmiento”, 14 (1993), págs. 8-12.

González García, Miguel Ángel, "El arquitecto Juan Ruiz de Pamames en Celanova”, Rudesindus: miscelánea de arte e cultura, 8 (2012), págs. 135-140.

González Muñoz, María del Carmen, "Galicia en 1571: población y economía, A Coruña-Sada, Eds. do Castro, 1982.

Jiménez Montañés, María Ángela, "La regulación del sistema productivo de la industria textil en el siglo XVI en Toledo: una aproximación", VII Encuentro de Trabajos sobre la Historia de la Contabilidad, León, Universidad de León, 2010, págs.1-22.

Jiménez Montañés, María Ángela, "La industria textil y su regulación en el siglo XVI: caso particular de Toledo", Pecnia. Revista de la Facultad de Ciencias Económicas y Empresariales, 14 (2012), págs. 107-132.

López Carreira, Anselmo, A cidade de Ourense no século XV. Sociedade urbana na Galicia baixomedieval, Ourense, Deputación Provincial de Ourense, 1998.

López Díaz, María, "Ourense y su provincia al comienzo de los tiempos modernos", en $E l$ Reino de Galicia en la época del emperador Carlos V, Santiago de Compostela, Xunta de Galicia, 2000, págs. 505-550.

López Ferreiro, Antonio, "Bordados y bordadores de Santiago”, Galicia Histórica, 4 (1902), págs. 251-264. 
Meijide Pardo, Antonio, “Algunos recursos de Galicia: cáñamo y seda”, Revista de Economía de Galicia, 43-44 (1965), págs. 65-78.

Pérez Costanti, Pablo, "El arte en Galicia. Pintura a la aguja. Brosladores de los siglos XVI y XVII”, en Notas Viejas Galicianas, II, Vigo, s. n., 1925, págs. 337-342.

Pérez Costanti, Pablo, Diccionario de artistas que florecieron en Galicia durante los siglos XVI y XVII, Santiago, Imp. del Seminario C. Central, 1930.

Saavedra Fernández, Pegerto, "Desarrollo y crisis de la industria textil gallega. El ejemplo de la lencería, 1600-1840”, Cuadernos de Investigación Histórica, 7 (1983), págs. 113-132.

Saavedra Fernández, Pegerto, A Galicia no Antigo Réxime. Economía e Sociedade, III, A Coruña, Ed. Hércules, 1991, págs. 323-328.

Saavedra Fernández, Pegerto, "El textil en la Edad Moderna”, en Con-Fío en Galicia. Vestir Galicia. Vestir o Mundo, Santiago de Compostela, Xunta de Galicia, 2016, págs. 243-257.

Santos Vaquero, Ángel, La industria textil sedera de Toledo, Cuenca, Ediciones de la Universidad de Castilla-La Mancha, 2010.

Sobrado Correa, Hortensio, "Economía rural y vida campesina en la Galicia oriental en tiempos de Carlos V", en Eiras Roel, Antonio (coord.), El Reino de Galicia en la época del emperador Carlos V, Santiago de Compostela, Xunta de Galicia, 2000, págs. 205-259. 
